\title{
A Study to Analyse the Effectiveness of Computer Assisted Instructions (CAI) Programme on course related Motivation and Self-Efficacy of class 9th students in learning Biology
}

\author{
Suruchi ${ }^{1}$, Dr. S.S. Rana ${ }^{2}$ \\ ${ }^{1}$ (Research Scholar, M.D. University, Rohtak) \\ ${ }_{2}^{2}$ (Principal, T.R. College of Education, Sonepat)
}

\begin{abstract}
The focus of current study is to analyse the effectiveness of CAI on students motivation and self efficacy in learning Biology. For the study a quasi experimental design with a purposive sample of 50 class $9^{\text {th }}$ students was selected. Students were randomly selected and distributed into two groups with 25 in each. To evaluate their motivation and self efficacy SMTSL Questionnaire was administered as a pre test and post test. Outcomes of the study revealed that experimental group students improved their level of motivation and self efficacy after treatment with CAI whereas no considerable improvement was found in control group students who were taught by lecture method by the same teacher.
\end{abstract}

Keywords: CAI, Motivation, Self-Efficacy

\section{Introduction}

"Our students have different ways of learning. Some are visual learners, some kinaesthetic, some auditory. These learning preferences may influence what our students are paying special attention to" (Sprenger, 2003). Many educators believe that traditional lecture approach to teaching is ineffective compared to active learning methods (Marbach-Ad, Seal \& Sokolove, 2001; Jungst, Licklider \& Wiersema, 2003). The metaanalysis, published online on May24, 2014 in the "Proceedings of the National Academy of Sciences" concluded that teaching methods that make the students active participants rather a passive listener reduce failure rates and boost scores on exams. But the active participation by students is largely relying upon the interest, motivation and confidence of students. "If kids don't want to learn, you probably can't make 'em. Merriam-Webster (1993) defines motivation as "Something (need/desire) that causes a person to act" (p-759). Intrinsic motivation comes from within while extrinsic motivation is associated with reward and punishment. Visual learners get motivated with pictures, graphics, overhead transparencies, texts etc. While auditory learners like to listen, debate, discussions, audios etc. Our kinaesthetic or tactile learners need hands- on learning, learning by doing. Thus introducing technology in our class rooms has become a necessity. Use of computer technology not only improves teacher's effectiveness but also motivates students to learn and perform better in academics. Computer assisted instructions (CAI) includes positive impact on active learning, enrichment of collaborated learning, encouragement of greater students independence and task based teaching (Worthington etal. 1996; Prvan etal., 2002). There are several individual researches going on Motivation and CAI and Science learning but literature reviews shows that rarely any work is there which investigate the effectiveness of CAI on motivation and self-efficacy of students in learning science especially Biology. Consequently researcher opted to evaluate the effect of computer assisted instructions on the motivation and self-efficacy of secondary school students in learning biology.

\section{Operational Definitions Of The Terms Used}

MOTIVATION: It is a psychological feature that evokes or prompts an individual to act towards achieving a desired goal. A student with high motivation is highly active and energized to learn and assimilate new information and eager to perform better.

SELF- EFFICACY: Self efficacy is one's confidence about his/her capability to achieve a certain level of performance. A student with high level of self-efficacy take difficult tasks as challenge and are intrinsically motivated to achieve their goals.

CAI (Computer Assisted instructions): It is an interactive instructional technique whereby a computer is used to present the instructional material and monitor the learning of students. It is a combination of texts, graphics, pictures, audios, videos, animations etc. 
EFFECTIVENESS: for this study effectiveness of CAI is investigated on the basis of difference in the level of motivation and self-efficacy of students based on pre-test and post-test scores of SMTSL scale.

\section{Objectives Of Study:}

1) To develop a CAI programme for class IX students to learn biology lessons.

2) To study the effect of CAI on course related motivation of sec. School students in learning biology lessons.

3) To study the effect of CAI on course relevant self efficacy of sec. school students in learning biology.

\section{HYPOTHESES:}

1) There exists a significant effect of CAI on the course related motivation of secondary school students in learning biology.

2) There exists a significant difference in the motivation level of students of control group (taught through traditional lecture only method) and experimental group (taught through CAI plus lecture method) in learning biology.

3) There exists a significant effect of CAI on the course relevant self-efficacy of secondary school students in learning biology.

4) There exists a significant difference in the self-efficacy of students of control group (taught through traditional lecture only method) and experimental group (taught through CAI plus lecture method) in learning biology.

\section{Research Methodology:}

To study the effect of CAI on biology course related motivation and self-efficacy of secondary school students researcher opted for a pre-test and post-test quasi experimental method.

\section{PARTICIPANTS:}

To conduct the study quasi experimental design with a purposive sample was used by researcher. Seventy enrolled students from two intact sections of class nine from same school were exposed to Culture Fair Intelligence test (Catell and Catell) and Socio-Economic status scale (SESS-UR-KASS). On the basis of scores obtained 50 equated students were randomly distributed into two groups and after tossing a coin one group was assigned as Control group (25 students) and one as Experimental group (25 students).

\section{DATA GATHERING INSTRUMENTS:}

Treatment instrument CAI, for the study, was a self instructional interactive package developed by the researcher herself.

The data of the research was gathered using test instrument "Student Motivation Towards Science Learning" (SMTSL) questionnaire developed by Tuan, Chin And Shieh. The instrument is consisting of 35 items on six scales of various aspects of motivation including self efficacy. Items are constructed on a five- point likert scale ranging from 1 strongly disagree to 5 strongly agree.

SMTSL questionnaire was administered twice during the study, first as a pretest to both the groups and secondly as a post test after treatment of CAI to experimental group and traditional teaching method to control group.

\section{PROCEDURE}

CAI DEVELOPMENT: To carry out the study researcher first developed a computer assisted instructions programme for the selected biology chapters of class IX science NCERT curriculum.

Development of CAI includes selection of subject material, identification of target audience, defining instructional objectives, selection of suitable hardware and software, script writing, production of final programme and feedback from users and experts. The validity of developed CAI was established by subject experts and computer experts.

GROUP ASSIGNMENT: Administration of Culture Fair test of Intelligence and Socio-economic status scaleUR- KASS on IX class students selected on the basis of Purposive sampling. Equivalent fifty students on these scales were randomly distributed into two groups- experimental and control group , names assigned by tossing a coin.

PRE TEST: Students motivation towards science learning (SMTSL) questionnaire was administered to both the groups as a pre test to measure the level of motivation and self efficacy in the students.

TREATMENT: After the pre test, control group students were exposed to traditional method of teaching i.e. lecture method only whereas experimental group students were taught using CAI plus lecture by the reseracher. POST TEST: Students motivation towards science learning (SMTSL) questionnaire was again administered to both the groups as a post test to measure the level of motivation and self efficacy in the students after the treatment. 
A Study to Analyse the Effectiveness of Computer Assisted Instructions (CAI) Programme on....

\section{Data Analysis}

Data obtained after administering SMTSL as a pre test and post test on both the groups are tabulated as under-

1) To compare the motivation of the control group students and experimental group students.

Table-1

\begin{tabular}{|c|c|c|c|c|c|c|c|c|}
\hline \multirow[b]{2}{*}{ Group } & \multirow[b]{2}{*}{$\mathbf{n}$} & \multirow[b]{2}{*}{ Treatment } & \multicolumn{3}{|c|}{ PRE TEST } & \multicolumn{3}{|c|}{ POST TEST } \\
\hline & & & $\mathbf{M}$ & SD & $\mathbf{t}$ & $\mathbf{M}$ & SD & $\mathbf{t}$ \\
\hline Control & 25 & lecture only & 44.2 & 8.37 & \multirow{2}{*}{0.085} & 101.8 & 15.48 & \multirow{2}{*}{$6.14 \mathrm{E}-09$} \\
\hline Experimental & 25 & Lecture+CAI & 48.8 & 8.22 & & 132.88 & 7.33 & \\
\hline
\end{tabular}
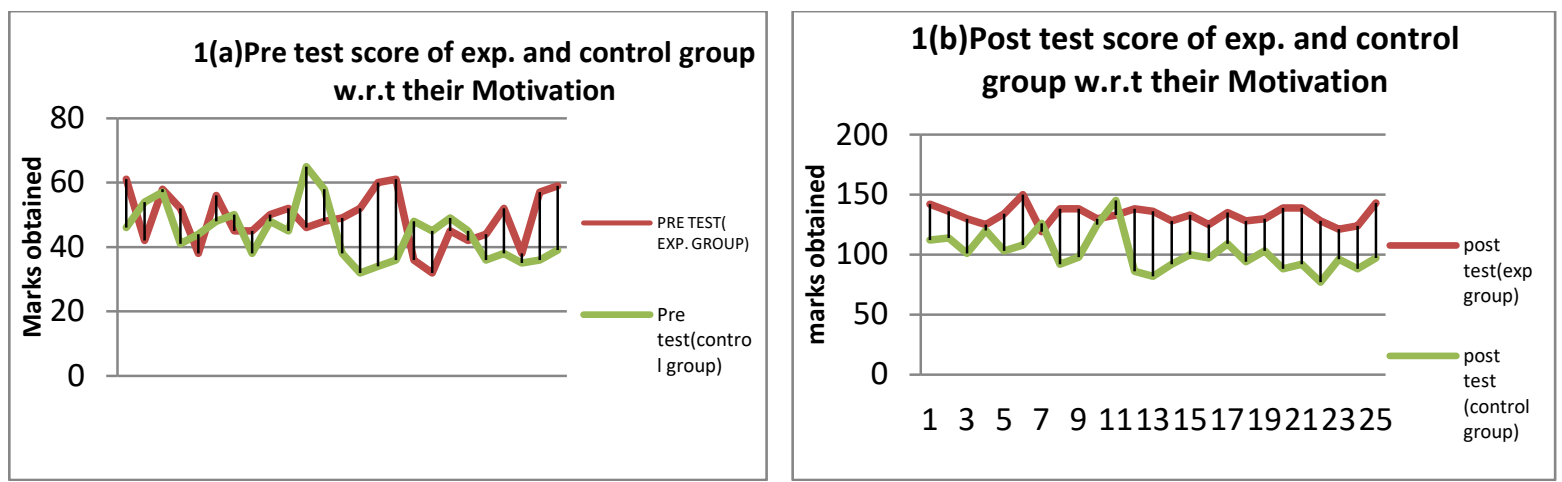

2) To compare the self efficacy of the control group students and experimental group students.

\begin{tabular}{|c|c|c|c|c|c|c|c|c|}
\hline \multirow{3}{*}{ Group } & \multirow{3}{*}{ n } & \multirow{3}{*}{ Treatment } & \multirow{2}{*}{\multicolumn{3}{|c|}{ PRE TEST }} & \multirow{2}{*}{\multicolumn{3}{|c|}{ POST TEST }} \\
\hline & & & & & & & & \\
\hline & & & $\mathbf{M}$ & SD & $\mathbf{t}$ & $\mathbf{M}$ & SD & $\mathbf{T}$ \\
\hline Control & 25 & lecture only & 16.32 & 1.79 & \multirow{2}{*}{0.552} & 21.88 & 3.24 & \multirow{2}{*}{$1.45 \mathrm{E}-05$} \\
\hline Experimental & 25 & Lecture+CAI & 16.6 & 2 & & 27.72 & 3.14 & \\
\hline
\end{tabular}
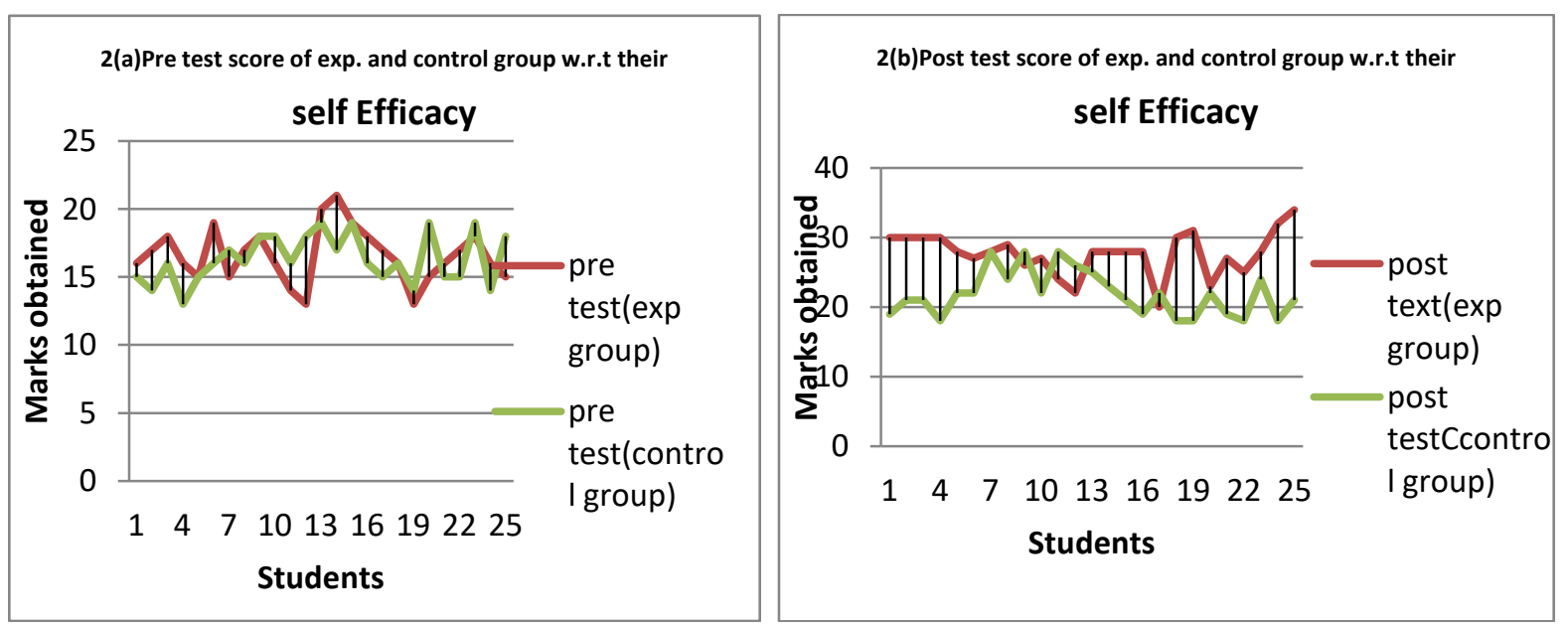

3) To compare the motivation of the control group students before and after the treatment.

\begin{tabular}{|c|c|c|c|c|}
\hline \multicolumn{6}{|c|}{ Control Group (lecture only) } \\
\hline SMTSL & $\mathrm{n}$ & $\mathrm{M}$ & $\mathrm{SD}$ & $\mathrm{t}$ \\
\hline Pre test & 25 & 44.42 & 8.47 & \multirow{2}{*}{$1.45 \mathrm{E}-17$} \\
\hline post test & 25 & 102 & 15.78 & \\
\hline
\end{tabular}




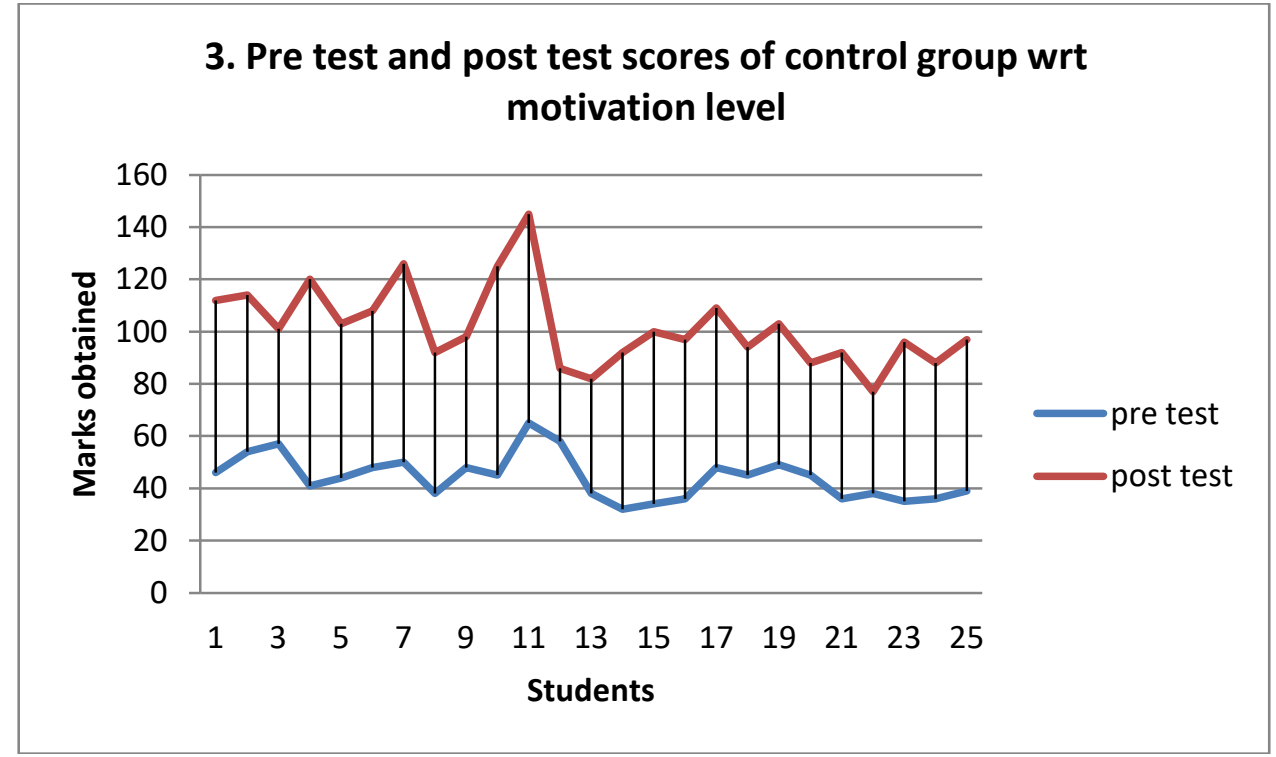

4) To compare the self effficacy of the control group students before and after the treatment.

\begin{tabular}{|c|c|c|c|c|}
\hline \multicolumn{5}{|c|}{ Control Group (lecture only) } \\
\hline SMTSL & $\mathrm{n}$ & $\mathrm{M}$ & $\mathrm{SD}$ & $\mathrm{t}$ \\
\hline Pre test & 25 & 16.25 & 1.80 & \multirow{2}{*}{$2.65 \mathrm{E}-10$} \\
\hline post test & 25 & 21.92 & 3.31 & \\
\hline
\end{tabular}

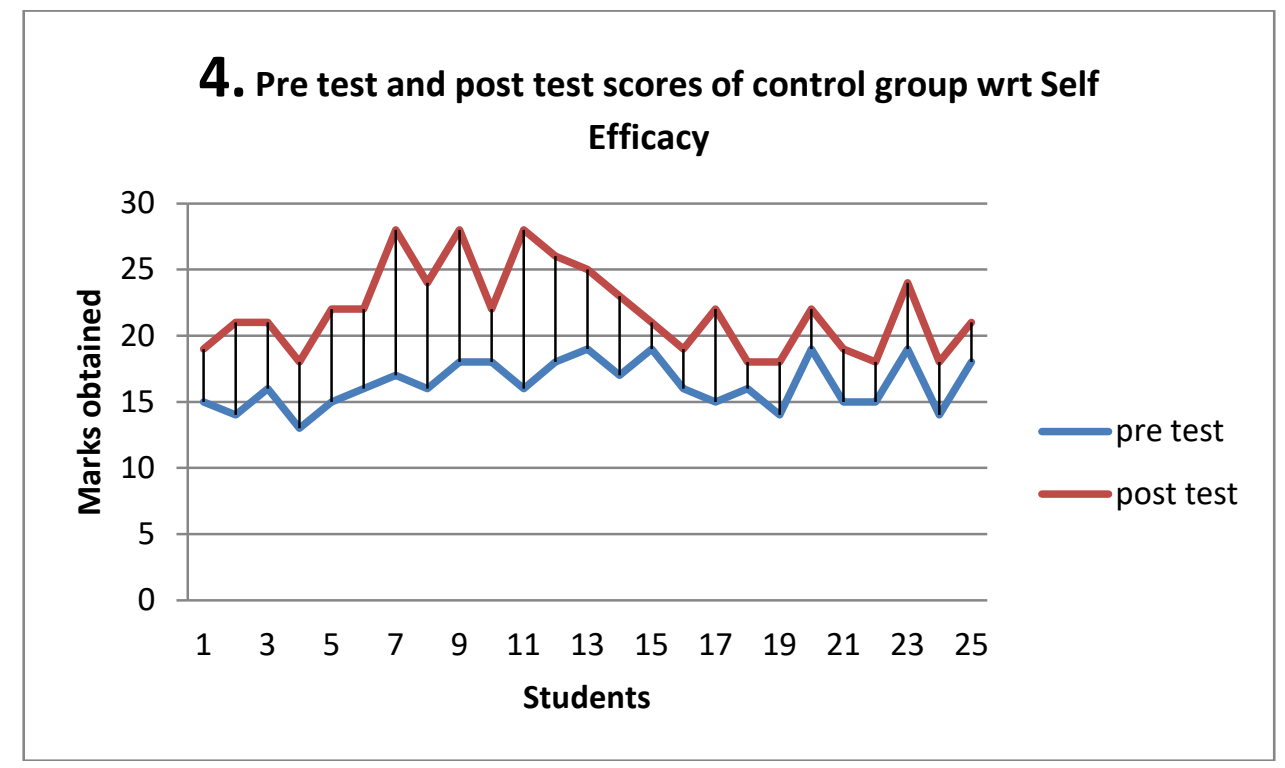

5) To compare the motivation of the experimental group students before and after the treatment.

\begin{tabular}{|c|c|c|c|c|}
\hline \multicolumn{5}{|c|}{ Experimental Group (lecture+CAI) } \\
\cline { 1 - 3 } SMTSL & $\mathrm{n}$ & $\mathrm{M}$ & $\mathrm{SD}$ & $\mathrm{t}$ \\
\cline { 1 - 4 } Pre test & 25 & 48.37 & 8.12 & \multirow{2}{*}{$8.96 \mathrm{E}-24$} \\
\cline { 1 - 3 } post test & 25 & 132.45 & 7.17 & \\
\hline
\end{tabular}




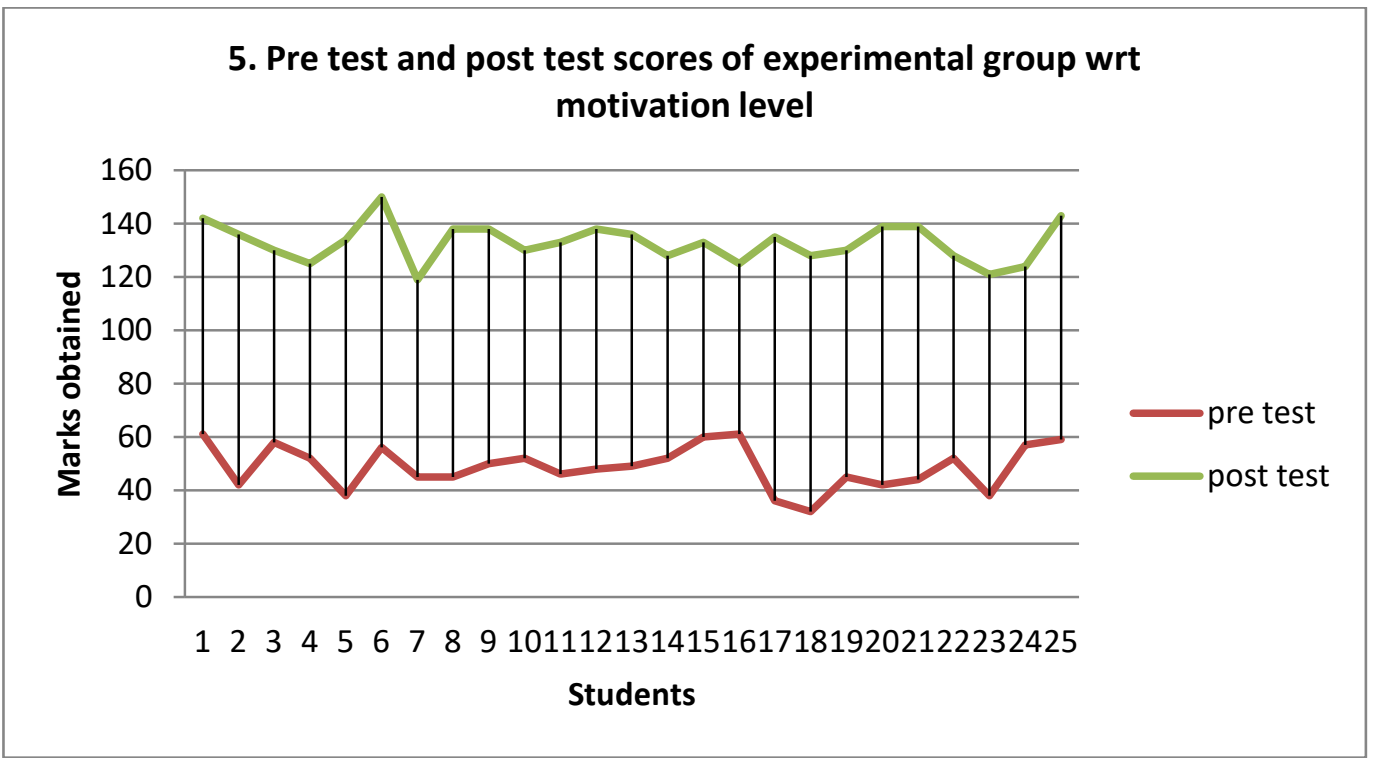

6) To compare the self effficacy of the experimental group students before and after the treatment.

\begin{tabular}{|c|c|c|c|c|}
\hline \multicolumn{5}{|c|}{ Experimental Group (lecture+CAI) } \\
\cline { 1 - 3 } SMTSL & $\mathrm{n}$ & $\mathrm{M}$ & $\mathrm{SD}$ & $\mathrm{t}$ \\
\cline { 1 - 3 } Pre test & 25 & 16.67 & 2.01 & \\
\cline { 1 - 3 } post test & 25 & 27.45 & 2.91 & \multirow{2}{*}{$6.51 \mathrm{E}-14$} \\
\hline
\end{tabular}

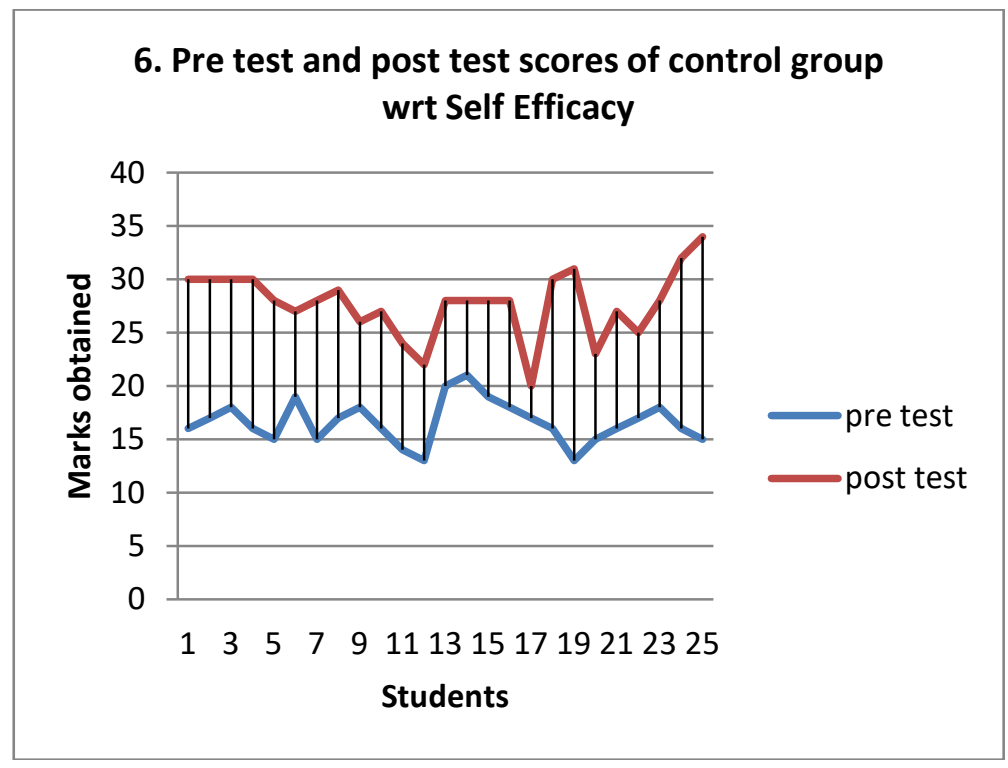

Findings of the study are

\section{Findings And Conclusion}

1) First hypothesis "There exists a significant effect of CAI on the course related motivation of secondary school students in learning biology" is accepted.

2) Hypothesis "There exists a significant difference in the motivation level of students of control group (taught through traditional lecture only method) and experimental group (taught through CAI plus lecture method) in learning biology" is accepted.

3) Hypothesis "There exists a significant effect of CAI on the course relevant self-efficacy of secondary school students in learning biology" is also accepted.

4) Hypothesis "There exists a significant difference in the self-efficacy of students of control group (taught through traditional lecture only method) and experimental group (taught through CAI plus lecture method) in learning biology" is accepted. 
From the study it is concluded that computer assisted instructions programme considerably affect the teaching and learning of Biology. It is found that the course related motivation level and self efficacy of students taught through CAI was increased profoundly. The students of control group who were taught through conventional lecture method didn't show thoughtful increase in level of motivation and self-efficacy. Findings of the study are in accordance with study of Spall and et al., 2003: prokop, Tuncer and Chuda, 2007; Cevik and Ekici, 2008

\section{Implications Of The Study:}

Motivation and confidence in students are important factors for any teacher to teach effectively. From the current studies it is revealed that CAI has a substantial effect on the motivation and self efficacy of students in learning Biology. So it is recommended that the teachers should adapt more audio visual based teaching strategies like CAI to make teaching more interesting and influential. The study is also helpful to the teachers in understanding that by improving the technology based teaching methods we can make the students learn novel and challenging tasks. This also increase their confidence to face the unexpected and hard academic problems. CAI makes the students more self reliant who are not ready to give up easily.

\section{References:}

[1] Marbach-Ad, G., Seal, O. \& Sokolove, P. (2001). Student Attitudes and Recommendations on Active Learning: A Student-Led Survey Gauging Course Effectiveness. Journal of College Science Teaching, 30(7), 434.

[2] JUNGST, S., LICKLIDER, L.L. \& WIERSEMA, J. (2003) 'Providing Support for Faculty Who Wish to Shift to a LearningCentered Paradigm in Their Higher Education Classrooms', The Journal of Scholarship of Teaching and Learning 3(3): 69-81.

[3] Prvan, T., Reid, A., \& Petocz, P. (2002). Statistical laboratories using Minitab, SPSS and Excel: A practical comparison. Teaching Statistics, 24 (2), 68-75.

[4] Tuan, H.L., Chin, C.C. \& Shieh, S.H. (2005). The development of a questionnaire for assessing students' motivation toward science learning. International Journal of Science Education, 27, 639-654.

[5] Branz-Spall, A. M., Rosenthal, R., \& Wright, A. (2003). Children of the road: Migrant students, our nation's most mobile population. Journal of Negro Education, 72, 55-62.

[6] Prokop, P., Prokop, M. \& Tunnicliffe, S. D. (2007). Is biology boring? Student attitudes toward biology. Journal of Biology Education, 42 (1), 36-39.

[7] Çevik, M. \& Ekici, G. (2008). Meslek lisesi öğrencilerinin biyoloji dersine yönelik tutumlarının farklı değişkenlere göre incelenmesi. 17.Ulusal Eğitim Bilimleri Kongresi 01-03 Eylül 2008 Sakarya Üniversitesi Eğitim Fakültesi, Sakarya.

Suruchi. "A Study to Analyse the Effectiveness of Computer Assisted Instructions (CAI) Programme on course related Motivation and Self-Efficacy of class 9th students in learning Biology." IOSR Journal of Research \& Method in Education (IOSR-JRME) 7.4 (2017): 30-35. 